\title{
Dynamic and Static Comparison of Beech Wood Dovetail, Tongue and Groove, Halving, and Dowel Joints
}

\author{
Amir Mollahassani, ${ }^{a}$ AmirHooman Hemmasi, ${ }^{a} *$ Habibollah Khademi Eslam, ${ }^{\text {a }}$ \\ Amir Lashgari, ${ }^{\mathrm{b}}$ and Behzad Bazyar ${ }^{\mathrm{a}}$
}

\begin{abstract}
Dynamic and static elastic properties beech wood joints were assessed. Conventional joints, namely dovetail, tongue and groove, dowel, and halving joints were prepared with beech wood (Fagus orientalis Lipsky) using polyvinyl acetate and cyanoacrylate adhesives. The results of the dynamic and static modulus of elasticity of the joints in this research indicated the highest reduction trends in halving, dowel, tongue and groove, and dovetail joints, respectively. The modulus of dovetail joint elasticity, its homogeneous joint texture, and lack of an extended adhesive line, corresponded to that of the jointed samples. The average static modulus of elasticity was approximately $10.5 \%$ lower than that of the dynamic modulus of elasticity. The results of the Student's t-test indicated a significant difference between the mean of dynamic and the mean of static modulus of elasticity, significance at $5 \%$ level and the Pearson correlation test indicated that the dynamic and static modulus of elasticity of the samples were significant at the $5 \%$ level and indicated a positive correlation. Based on the observed correlation in the dynamic and static tests' results, using these methods, dynamic assessment of NDTs may be regarded as an appropriate alternative in standardizing destructive static testing for wood assessment and categorization.
\end{abstract}

Keywords: Dovetail joint; Tongue and groove joint; Halving joint; Dowel joint; Dynamic and static assessment; Modulus of Elasticity

Contact information: a: Department of Wood and Paper Science and Technology, Faculty of Natural Resources and Environment, Science and Research Branch, Islamic Azad University, P.O. Box 14515/775, Tehran, Iran; b: Department of Wood Science and Technology, Karaj Branch, Islamic Azad University, P.O.Box31485-313, Karaj, Iran;*Corresponding author: h_hemmasi@srbiau.ac.ir

\section{INTRODUCTION}

Joints are among the most important components found in all wooden structures, while the scientific knowledge on them is limited. Joints provide coherence in the components and make the structure firm and stable. Consequently, success in applying wood as a construction material depends on how the wide variety of joints behave.

Adhesive bonding technology has played an essential role in the development and growth of the rehabilitation and repair of timber structures. The ability of a structural joint to maintain satisfactory long-term performance, often in severe environments, is an important requirement of a structural adhesive joint (Custodio et al. 2009). Adhesive joints may lose strength and become destroyed when subject to humidity, temperature, and other weather-related challenges.

Here, mere production of a reliable joint is not enough. Rather, it also is important that the joint hold firm when it is first applied. Because a head-to-head miter joint with a chemical connector (adhesive) is not sufficient on its own, normally joints 
such as dovetail, dowel, spline, biscuit, and movable groove are applied to strengthen the miter joints (Maleki et al. 2012).

Due to the ease in making joints with pins, they are extensively used in the modern furniture industry. Accordingly, there exist many studies on this issue. Zhang and Eckelman (1993) revealed that an increase the pins diameter (6 to $11 \mathrm{~mm}$ ) and an increase in the penetration depth (6 to $11 \mathrm{~mm}$ ) in each joint component would have a meaningful effect on the resistance against the bending moment of joints made of particle board with one pin. Kurt et al. (2009) assessed the bearing strength of wooden pins in particle board and medium density fiber board (MDF). The smoother the surface of the pins and tongue, the greater was the adhesion effect between the joined components.

Latibari et al. (2005) assessed the effects of the type, diameter, and degree of pin freedom on the shear strength of joints made of particle board. Their results indicate that the treaded pins with a10 $\mathrm{mm}$ diameter, a penetration depth four times the diameter, and a freedom degree of $0.5 \mathrm{~mm}$ or $0.25 \mathrm{~mm}$ had higher resistance against loads imposed. Eckelman and Haviarova (2006) studied the joinery of school chairs with pinned tongue and groove joints, with and without adhesive, and found that the strength of 0.125 diameter tongue joints with adhesive was improved by over $80 \%$ when compared to the same without adhesive. Their findings indicate that tenon joints may be fixed only by pins and applying adhesive with pins would increase the cost. Ghofrani and Nouri (2009) assessed the side shear strength of different types of wooden dowel joints and MiniFix joints on MDF; they found no significant difference between the screwed joints and other joints, while screwed joints showed the highest strength. Both the diameter and adhesive type are equally important criteria in wooden dowel joint as to their shear strength. Because the treaded wooden dowel joints are static, any fractures due to pressure and shear stress occur inside the board.

Derikvand et al. (2013) assessed the effects of different wood types on moving tenons and the penetration length of tenons on the resistance of the joint; they found that an increase in the penetration length of the moving tenon increased the between the joints connection strength. Their results indicate that the wood type applied in making the moving tenon had a considerable effect on the ability in holding the connections, because beech wood has a smooth surface and a high shear strength parallel to the fibers, making it the most effective wood to make tenons. Maleki et al. (2012) assessed the effects of the distance between the tails in a dovetail joints of 1,2 , and $3 \mathrm{~cm}$, and the joiner type in two variants of butterfly and $\mathrm{H}$ dovetails, on the tension tolerance capacity of miter corner joints made of particle board and MDF. They found that the tension tolerance capacity of a $\mathrm{H}$ dovetail miter joint is higher than that of the butterfly dovetail miter joint.

Maleki et al. (2013) assessed the effects of the adhesive type and the height of the dovetail joiner on the tension tolerance capacity of miter corner joints made of particle board and MDF. The results revealed that the tension tolerance capacity of joints using cyanoacrylate (CA) adhesives is higher than that of the joints that used with polyvinyl acetate (PVAc) adhesives or without.

The available studies on the extensive use of dovetail, tongue and groove, and halving and dowel joints in wooden structures are not enough. Thus, more studies are necessary to evaluate the mechanical characteristics of these joints. In this study the characteristics of the mentioned joints are of concern, with respect to their static and dynamic aspects. 


\section{EXPERIMENTAL}

In this study, first, 90 straight-grown beech (Fagus orientalis Lipsky) trees were transversely cut into samples of $360 \mathrm{~L} \times 50 \mathrm{~W} \times 24 \mathrm{H}$ mm dimensions and kept in the climatic test room for 2 weeks, as specified in ISO 3129(2012). Next, they became subject to free bending vibration in a two-sided free beam test, and then the samples with the highest correlation $>0.98$, between the $1^{\text {st }}$ and $3^{\text {rd }}$ vibration modes, were selected for the test. This test sample selection was according to Hossein et al. (2009), where out of the preliminary samples, 80 were qualified for test. These samples become subject to a bending vibration test after their dimensions and weights were measured.

Sound recording files were made through Audacity $\left(3^{\text {rd }}\right.$ version, The Audacity Team, Carnegie Mellon University, Pittsburgh, PA, USA), and the audio files were read subject to bending vibration through NDT-lab® portable system setup at the same frequency. After all dimensions and weights had been added to the system, calculations related to the correlation coefficient between the first three vibration modes and the run shear modulus were completed. The elastic characteristics of the beech wood were studied, including the modulus of elasticity (MOE). The acoustic efficiency coefficient $(K)$ and the acoustic conversion coefficient (ACE) were assessed through free longitudinal vibrations in a two-sided free beam, as shown in Fig. 1, in the radial (LR) and tangential (LT) directions.
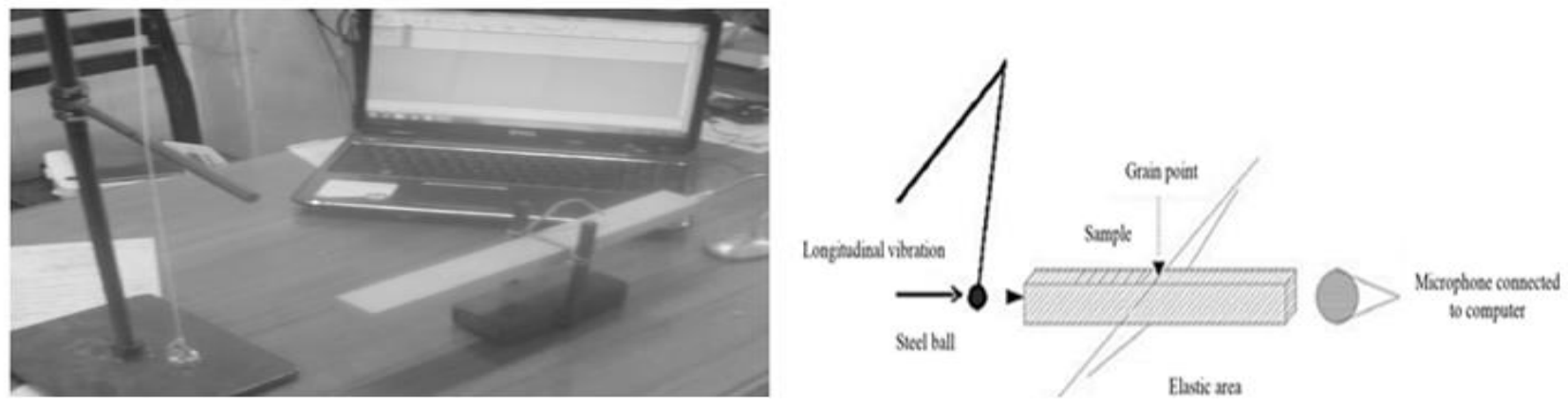

Fig. 1. Schematic representation of longitudinal vibration in a two-sided free beam (Brancheriau et al. 2010)

The wave length volume for the $1^{\text {st }}$ mode of the longitudinal vibrations in the sample length, and the frequency and wave length, the velocity of the sound wave volumes in the longitudinal direction of the samples were calculated through Eq. (1),

$$
V=2 l f
$$

where $V(\mathrm{~m} / \mathrm{s})$ is the sound velocity in the longitudinal direction of the wood, and $f(\mathrm{~Hz})$ is the frequency for the $1^{\text {st }}$ mode of longitudinal vibrations.

The dynamic longitudinal elastic modulus was calculated through Eq. 2,

$$
E=\rho V^{2}
$$

where $\rho\left(\mathrm{kg} / \mathrm{m}^{3}\right)$ is the specific weight and $E(\mathrm{~Pa})$ is the longitudinal elastic modulus.

The damping factor is calculated from the analysis of how the sample vibration amplitude drops over time using the Fourier series spectrum as calculated through Eq. 3,

$$
\tan \delta=\frac{\lambda}{\pi}
$$


where $\tan (\delta)$ is the damping factor and $\lambda$ is the logarithmic decrement that is calculated in a logarithmic scale based on sound attenuation. The acoustic coefficient $K$ and the acoustic conversion efficiency $A C E$ are among the most important acoustic factors for woods used in sound resonation plates, and they are calculated through Eqs. 4 and 5, respectively,

$$
\begin{gathered}
K=\sqrt{E / \rho^{3}} \\
A C E=\frac{K}{\tan (\delta)}
\end{gathered}
$$

where $K$ is the acoustic coefficient and $A C E\left(\mathrm{~m}^{4} / \mathrm{Kg} . \mathrm{s}\right)$ is the acoustic conversion efficiency.
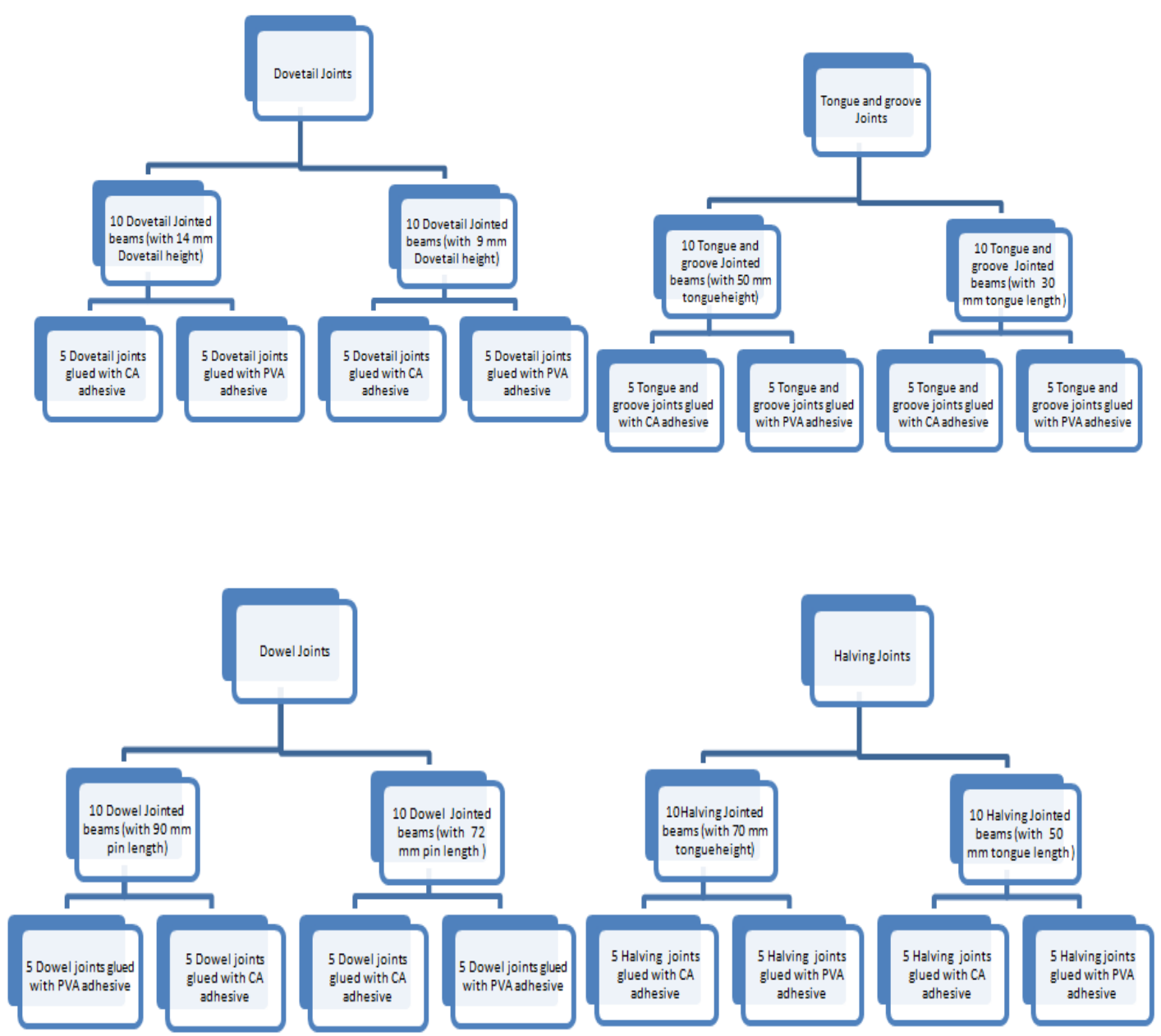

Fig. 2. Patterns and instructions applied for jointed beams

The variable factors of each one of the joints used here are: two types of adhesives (cyanoacrylate and polyvinyl acetate) and two tenon heights, lengths, or joiner pin lengths. There were 20 samples of $360 \mathrm{~L} \times 50 \mathrm{~W} \times 24 \mathrm{H} \mathrm{mm}$; dovetail, tongue and groove, halving, and dowel joints for each test. These joints' dimensions were based on studies run by (Horwood 1999; Haviarova et al. 2001; Eckelman and Haviarova 2006; Noll 2007). 
The samples were divided in four groups of 20. The characteristics of each group, as presented in Fig. 2 with two adhesives, were examined as follows: 1) For dovetail joints, the effect of butterfly dovetail with two heights of 9 and $14 \mathrm{~mm}$; 2) For dowel joints, the effect of dowel $8 \mathrm{~mm}$ diameter with two heights of 72 and $90 \mathrm{~mm}$; 3) For tongue and groove joints, the effect of tenon with two lengths of 30 and $50 \mathrm{~mm}$; and 4) For halving joints, the effect of tenon with two lengths of 50 and $70 \mathrm{~mm}$.

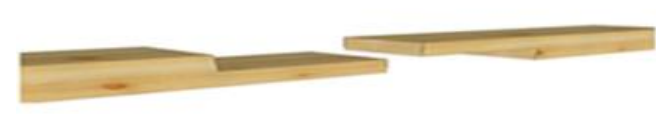

a

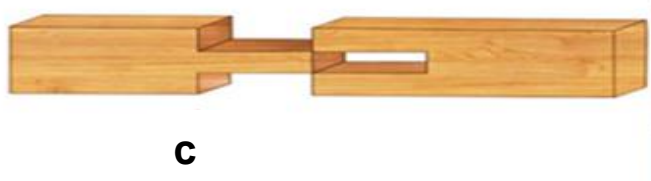

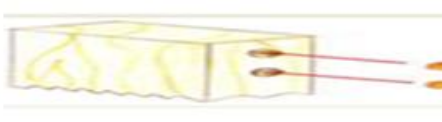

b

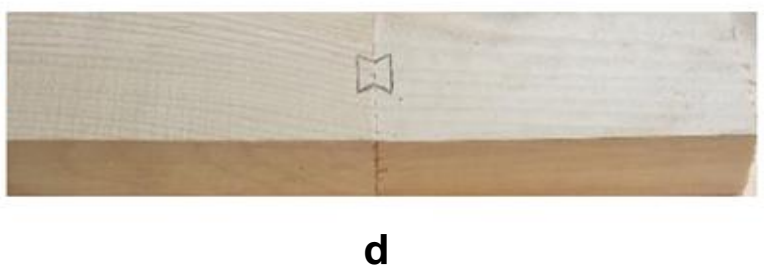

Fig. 3. a: Halving joint, b: Dowel joint, c: Tongue and groove joint, d: Dovetail joint

The halving, dowel joint, tongue and groove, and dovetail joint samples were all glued and fixed with clamps. The clamps were released from the joints after they were fully established, and the specimens were kept in a climatized room at $20{ }^{\circ} \mathrm{C}$ and $65 \% \mathrm{RH}$.

Two types of adhesives with the following characteristics were used in this study. The first was Polyvinyl Acetate (PVAc) adhesive. It is a type of adhesive that contains a solids content of $60 \%$, a viscosity of 12 to $18 \mathrm{~Pa}$.s at a temperature of $20{ }^{\circ} \mathrm{C}$, and density of $1.08 \mathrm{~g} / \mathrm{cm}^{3}$. The second was Cyanoacrylate (CA) adhesive. It contains a solids content of $100 \%$, a viscosity of 1.3 to1.5 Pa.s. and density of $1.06 \mathrm{~g} / \mathrm{cm}^{3}$. The adhesives were used in accordance with the manufacture's recommendations.

Bending vibration tests were run to assess the elastic characteristics of beech wood. To analyze the data obtained, the statistical method of variance analysis was run by applying SPSS Software (IBM, Version 22, Armonk, NY). Moreover, the mechanical characteristics and the elastic constants of beech wood were assessed in an NDT-lab® portable system setup (Roohnia et al. 2006) environment.

\section{RESULTS AND DISCUSSION}

In assessing the modulus of elasticity dynamism, the confidence level of the joint types, adhesive types, and joint sizes was of 95\% significance. In assessing the interaction of effective factors, the joint type $\times$ joint size was significant at the $95 \%$ confidence level. To assess the dynamism of the audio characteristics of the samples, the effects of different joint types, adhesive types, and joint sizes were significant at the $95 \%$ confidence level. To assess the interaction of the effective factors, the interaction of the joint type $\times$ joint size with the acoustic coefficient and samples damping were significant at $95 \%$ confidence, as shown in Tables 1 through 3. 
Table 1. Analysis of Variance Aimed at the Effect of the Joint Type and Adhesive Type and Joint Size on the Modulus of Elasticity

\begin{tabular}{|l|c|c|c|c|}
\hline Dependent Variable: MOE & $\mathrm{df}$ & Mean Square & $\mathrm{F}$ & Sig. \\
\hline Source & 31 & 32437158304 & 100.438 & .000 \\
\hline Corrected Model & 1 & 11998210735 & 37151.030 & .000 \\
\hline Intercept & 3 & 16343283924 & 50.605 & .000 \\
\hline Joint type & 1 & 10072768902 & 31.189 & .000 \\
\hline Adhesive type & 1 & 76215705742 & 235.993 & .000 \\
\hline Joint size & 3 & 4202822548 & .130 & .942 \\
\hline Joint type * adhesive type & 3 & 20177171026 & 6.248 & .001 \\
\hline Joint type * Joint size & 1 & 43909000680 & .014 & .907 \\
\hline Adhesive type * Joint size & 3 & 12789993411 & .040 & .989 \\
\hline $\begin{array}{l}\text { Joint type * adhesive type * joint } \\
\text { size }\end{array}$ & 128 & 32295768427 & & \\
\hline Error & 80 & & & \\
\hline Total & 79 & & \\
\hline Corrected Total & \multicolumn{5}{|l}{} \\
\hline R-Squared = .961 (Adjusted R-Squared $=.951)$ & \\
\hline
\end{tabular}

Table 2. Analysis of Variance Aimed at the Effect of the Joint Type and Adhesive Type and Joint size on the Acoustic Coefficient

\begin{tabular}{|c|c|c|c|c|}
\hline \multicolumn{5}{|l|}{ Dependent Variable: Acoustic Coefficient } \\
\hline Source & $\mathrm{df}$ & Mean Square & $\mathrm{F}$ & Sig. \\
\hline Corrected Model & 31 & 10.561 & 41.025 & .000 \\
\hline Intercept & 1 & 11448.918 & 44475.420 & .000 \\
\hline Joint type & 3 & 2.342 & 9.097 & .000 \\
\hline Adhesive type & 1 & 2.297 & 8.922 & .003 \\
\hline Joint size & 1 & .878 & 3.409 & .067 \\
\hline Joint type * adhesive type & 3 & .015 & .060 & .981 \\
\hline Joint type * Joint size & 3 & 1.242 & 4.826 & .003 \\
\hline adhesive type * Joint size & 1 & .001 & .003 & .959 \\
\hline joint type * adhesive type * joint size & 3 & .032 & .123 & .947 \\
\hline Error & 128 & .257 & & \\
\hline Total & 80 & & & \\
\hline Corrected Total & 79 & & & \\
\hline R-Squared $=.909$ (Adjusted R-Squared $=.886)$ & & \\
\hline
\end{tabular}


Table3. Analysis of Variance Aimed at the Effect of the Joint Type and Adhesive Type and Joint size on the Damping

\begin{tabular}{|c|c|c|c|c|}
\hline \multicolumn{5}{|c|}{ Dependent Variable: Damping } \\
\hline Source & $d f$ & Mean Square & $\mathrm{F}$ & Sig. \\
\hline Corrected Model & 31 & .007 & 8.255 & .000 \\
\hline Intercept & 1 & .645 & 780.316 & .000 \\
\hline Joint type & 3 & .010 & 11.869 & .000 \\
\hline Adhesive type & 1 & .023 & 28.088 & .000 \\
\hline Joint size & 1 & .008 & 10.168 & .002 \\
\hline Joint type ${ }^{*}$ adhesive type & 3 & .002 & 1.844 & .142 \\
\hline Joint type * Joint size & 3 & .008 & 9.714 & .000 \\
\hline adhesive type * Joint size & 1 & .001 & 1.295 & .257 \\
\hline $\begin{array}{c}\text { joint type * adhesive type }{ }^{*} \text { joint } \\
\text { size }\end{array}$ & 3 & .003 & 3.726 & .013 \\
\hline Error & 128 & .001 & & \\
\hline Total & 80 & & & \\
\hline Corrected Total & 79 & & & \\
\hline R-Squared $=.667$ (Adjusted R-S & & & & \\
\hline
\end{tabular}

In the experimental samples, the four different joint types (dovetail, dowel, tongue and groove, and halving), different joint part size, and the use of polyvinyl acetate or cyanoacrylate adhesives; the elastic and acoustic characteristics of these joints revealed a decrease when compared to the control samples (non-jointed). When the dovetail joint height was increased from 9 to $14 \mathrm{~mm}$, the tongue and groove joint tenon length became 50 from $30 \mathrm{~mm}$, and when the dowel joint pin length was increased from 36 to $45 \mathrm{~mm}$, and the halving joint tenon length became 70 from $50 \mathrm{~mm}$, thus showing an improvement in the elastic characteristics (Fig. 4). For all experimental joints, use of a cyanoacrylate adhesive yielded a greater improvement in the elastic characteristics when compared to the polyvinyl acetate adhesive (Fig. 4).

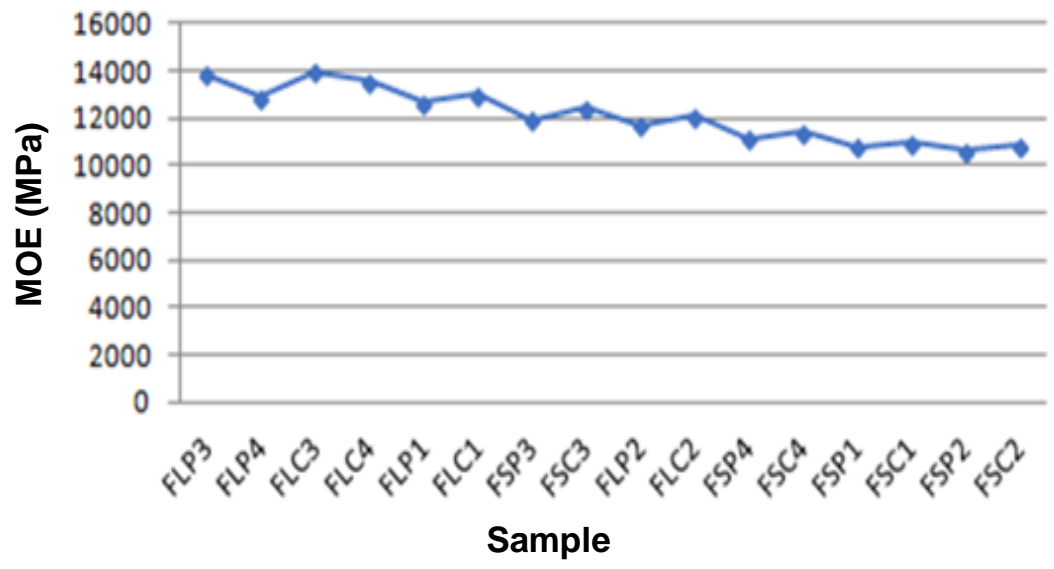

Key: $\mathrm{F}=$ beech; $\mathrm{L}=$ large joint; $\mathrm{S}=$ small joint; $\mathrm{P}=$ polyvinyl acetate adhesive; $\mathrm{C}=$ cyanoacrylate adhesive; 1 = dowel joint; $2=$ halving joint; $3=$ dovetail joint; $4=$ tongue and groove joint

Fig. 4. Comparison of dynamic modulus of elasticity of the experimental joints 
In dovetail joints where cyanoacrylate adhesive was employed, the modulus of elasticity was higher than that of the other joints. Tongue and groove joints had a higher modulus of elasticity than that of both the dowel and halving joints, and dowel joints had a higher modulus of elasticity than that of the halving joints. The average difference of the joints used in this study were of significant with $95 \%$ confidence. Dovetail joints with a14 mm handmade length with cyanoacrylate adhesive showed the least effect on the acoustic characteristics of beech wood, while halving joints, especially those with a shorter tenon length $(50 \mathrm{~mm})$ and made with polyvinyl acetate adhesive, were considerably more effective in reduction the acoustical properties.

For the static analysis of the elastic characteristics of beech wood, in dovetail, dowel, tongue and groove, and halving joints, the effects of joint type, joint size, and adhesive type were significant at the $95 \%$ confidence level. Moreover, among the interaction effects of the studied variables, the size $\times$ joint effect were significant at $95 \%$ confidence level. The effect of the other studied variables were not significance at $95 \%$ confidence. In terms of the highest level of elasticity in the experimental joints, the static test results were similar to those of the dynamic test results, i.e., the dovetail joint revealed the highest static modulus of elasticity and the halving joint the lowest. The static modulus of elasticity average was $10.5 \%$ lower than that of the dynamic modulus of elasticity with a confidence interval of $7.2 \%$ to $13.8 \%$ with a $95 \%$ confidence level.

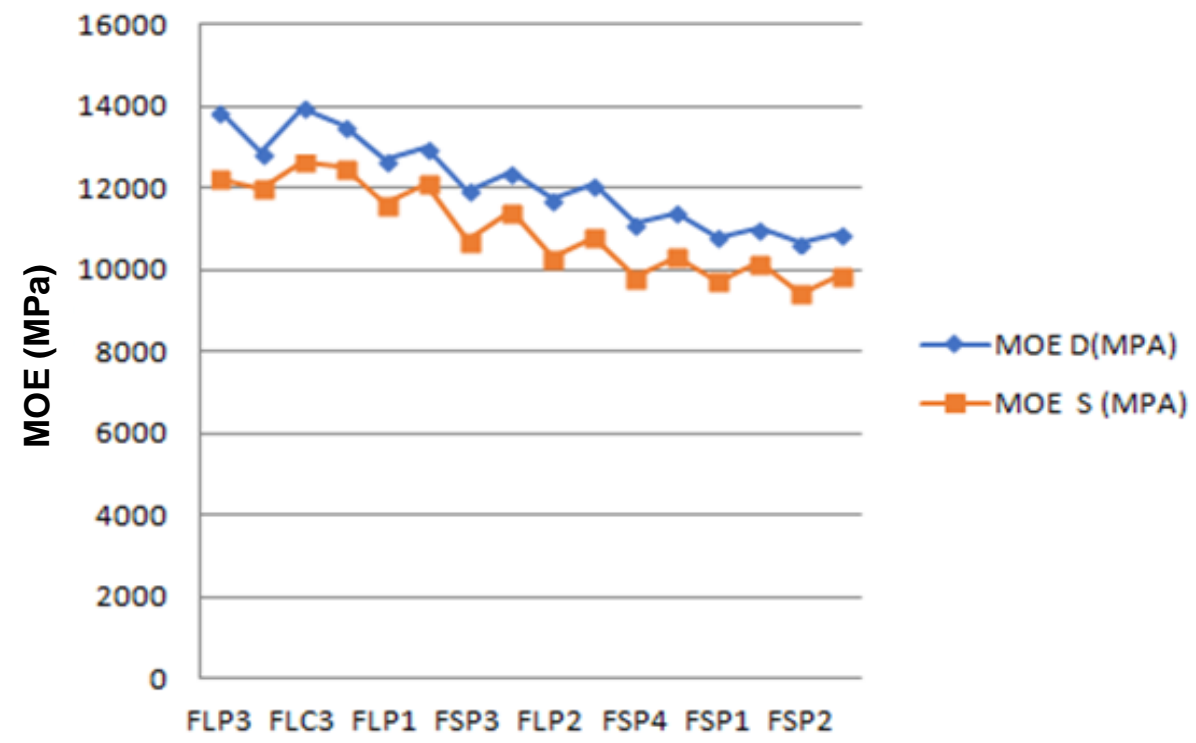

Key: $\mathrm{F}=$ beech; $\mathrm{L}=$ large joint; $\mathrm{S}=$ small joint; $\mathrm{P}=$ polyvinyl acetate adhesive; $\mathrm{C}=$ cyanoacrylate adhesive; $1=$ dowel joint; $2=$ halving joint; $3=$ dovetail joint; $4=$ tongue and groove joint

Fig. 5. Comparison of dynamic and static modulus of elasticity of the experimental joints

The results of the Student's t-test indicated a significant difference between the mean of dynamic and the mean of static modulus of elasticity, although the dynamic modulus of elasticity was higher than that of the static modulus. The Pearson correlation test indicated that the dynamic and static modulus of elasticity of the samples were significant at the $5 \%$ level and showed a positive correlation. 
In this study, higher modulus of elasticity were obtained with an increase in the tenon length, the dovetail height, and the wooden pin length in dowel joints. An increase in the dovetail height from 9 to $14 \mathrm{~mm}$, an increase in the tenon length from 30 to $50 \mathrm{~mm}$ in tongue and groove joints, an increasing the pin length from 36 to $45 \mathrm{~mm}$ in dowel joints, and an increase in the tenon length from 72 to $90 \mathrm{~mm}$, all yielded higher elasticity for both the dynamic and static analyses. These results were confirmed with the findings of other studies, which indicated that an increase in the surface area of the tenons had a special effect on the tension resistance capacity under tensile and compressive loads (Dalvand et al. 2012; Maleki et al. 2012; Drikvand et al. 2013; Kahvand et al. 2013). It may be stated that an increase in the connection surface area of the tenon, the amount of glued surface increased and led to greater overall strength of the joint and with a more homogenous joint location. Adhesives increased both the density at the joint location and the elastic modulus of the joints. For dovetail joints, an increase in the dovetail height increased the tension resistance capacity, which may be attributed to the larger joiner surface and the joint components. When the contact surface areas between joint components and joiner increased, the tensile strength capacity increased as well.

For dowel joints, an increase in the wooden pin diameter and length led to a larger perimeter, consequently a larger area, which increased the adhesion surface and overall strength of the joint. The results of the static and dynamic analyses of the joints run here indicate that the tongue and groove joint have a higher modulus of elasticity than the dowel and halving joints. This finding corresponds with those of others (Eckelman 2003; Ghofrani and Noori 2009), where the samples with equal surface and thickness, the tongue and groove joints are stronger than wooden dowel joints. The rectangular shape of the tongue and groove joint provides greater strength and stability to the joint, and it is obvious that tongue and groove joints are more homogenous than the wooden dowel joints. This may be attributed to the use of different wood types for the pins in dowel joints. Moreover, for wooden dowel joints, the pins are located in longer joint holes, and pin tolerance the joint holes is effective relative to the strength of the joints. The treads of the wooden pins, combined with the in ability of the joint to move, can cause a fracture in place. For dowel joints, the adhesive lines are in two opposite pieces or along the entire wood length in dowel joints, while in tongue and groove joints, the adhesive lines are on one side; therefore, wooden dowel joints are weaker than tongue and groove joints. In all available the experimental run on joints studied had reduced dynamic and static modulus of elasticity and acoustic characteristics when compared to the non-joined samples (control samples). The acoustic coefficient was influenced by both the modulus of elasticity and the density parameter, where, as to density, it was much greater than modulus of elasticity parameter in terms of the acoustic coefficient. In jointed samples, this decrease may be due to an increase in density of the samples after the addition of a joint. Moreover, an increase in density may be attributed to an increase in density caused by polyvinyl acetate and cyanoacrylate adhesives when compared to non-jointed samples. Among the joints assessed here, dovetail joints exhibited the lowest effect on the acoustic characteristics compared to non-jointed samples, which is in correspondence with the findings by Wegst (2006) and Obataya and Norimoto (1999). The cited authors reported are verse relation between the modulus of elasticity and damping. A decrease in damping resulted in an increase in the ACE.

The static and dynamic analyses indicated that the modulus of elasticity of the experimental sample, as well as the dynamic and static modulus of elasticity were significantly different at the $95 \%$ confidence level with a positive correlation. Results 
obtained from the Student's t-test indicated a significant difference between the mean of dynamic and the mean of static elasticity modulus, and the Pearson correlation test indicated that the dynamic and static modulus of elasticity of the samples were significantly different at the $5 \%$ level with a positive correlation. This corresponds with the findings of Bodig and Jayan (1993) and Biechele et al. (2010).

At this point, non-destructive dynamic tests are recommended as an alternative to destructive static methods, because in the latter, samples do not break, no time is wasted, and they make the visual, X-ray, ultrasound, acoustic, vibration, etc. inspection of the methods possible. These non-destructive dynamic analysis methods reduce the overall time and cost, and since they do not cause damage, they reduce the overall production waste. They also increase efficiency by increasing the quality of the products. The possibility of continuous analysis and greater control of the products may be effective in the prediction and damage prevention through these tests.

\section{CONCLUSIONS}

1. The effects of adhesive type, joint type, and joint size, together with the interaction between last two on the modulus of elasticity and acoustic coefficient and damping were significant at the $5 \%$ level in both the dynamic and static tests.

2. In terms of the highest elasticity level in the experimental joints, the static test revealed the same results as those of the dynamic test, i.e., the dovetail joint revealed the highest elastic modulus and the halving joint had the lowest elastic modulus.

3. Application of cyanoacrylate adhesive led to higher modulus of elasticity, compared to samples glued with polyvinyl acetate adhesive.

4. The Student's t-test indicated a significant difference between the mean of dynamic and the mean of static modulus of elasticity, although the dynamic modulus of elasticity was higher than that of the static modulus, with a significance at the 5\% level. Moreover, according to the Pearson correlation test there was a positive correlation between these two elasticity quantities.

\section{REFERENCES CITED}

Biechele, T., Chui, Y.H., and Gong, M. (2010). "Assessing stiffness on finger-jointed timber with different non-destructive testing techniques," in: Proceedings of the Future of Quality Control for Wood Products, Edinburgh, UK. 4-7.

Bodig, J., and Jayne, B.A. (1993). Mechanics of Wood and Wood Composites (Persian Translation by G. Ebrahimi), Tehran University Press, Tehran.

Brancheriau, L., Kouchade, C., and Brémaud, I. (2010). "Internal friction measurement of tropical species by various acoustic methods," Journal of Wood Science 56(5), 371-379.

Custódio, J., Broughton, J., and Cruz, H. (2009). "A review of factors influencing the durability of structural bonded timber joint," International Journal of Adhesion and Adhesives 29(2),173-185. 
Dalvand, M., Maleki, S., Ebrahimi, G.H. and Haftkhani, A.R. (2012). "Determination of stress carrying capacity of doweled corner joints in framed furniture structure constructed of Fir," Iranian Journal of Wood and Paper Industries 5(1),21-32.

Derikvand, M., Ebrahimi, G. H., and Eckelman, C.A. (2013). "Effect of shoulder thickness on bending moment capacity of mortise and loose tenon joint," Iranian Journal of Wood and Paper Industries 28(1), 65-75.

Derikvand, M., Smardzewski, J., Ebrahimi, G., Dalvand, M., and Maleki, S. (2013). "Withdrawal force capacity of mortise and loose tenon T-type furniture joints," Turkish Journal of Agriculture and Forestry 37(3), 377-384.

Eckelman, C.A. (2003). Textbook of Product Engineering and Strength Design of Furniture, Purdue UniversityPress, West Lafayette, Indiana.

Eckelman, C., and Haviarova,E. (2006). "Performance tests of school chairs constructed with round mortise and tenon joints," Forest Products Journal 56(3), 51-57.

Ghofrani, M., andNouri, H. (2009). "Lateral holding strength of wooden dowel, screw and ready-to-assemble joints (RTA joints) constructed of Medium Density Fiberboard (MDF)," Iranian Journal of Wood and Paper Science Research 24(2), 219-231.

Haviarova, E., Eckelman, C., and Erdil, Y.Z. (2001). "Design and testing of environmentally friendly wood school chairs for developing countries," Forest Products Journal 51(3), 58-64.

Horwood, R. (1999). The Woodworker's Handbook, New Holland Publisher, London, UK. Hossein,M.A., Roohnia,M., and Shahverdi, M. (2009). "Some footprints of wood internal defects on three first mode-shapes of free vibration," in: $16^{\text {th }}$ International Symposium on Nondestructive Testing and Evaluation of Wood, Beijing, China, pp. 117-128.

ISO 3129 (2012). "Wood - Sampling methods and general requirements for physical and mechanical testing of small clear wood specimens," International Organization for Standardization, Geneva, Switzerland.

Kahvand, M., Omrani, P., and Ebrahimi, G. (2013). "Determination of bending moment resistance of T-type joints constructed with wood biscuit," Iranian Journal of Wood and Paper Industries 5(2), 47-58.

Kurt, Ş., Uysal, B., Özcan, C., and Yildirim, M.N. (2009). "The effects of edge banding thickness of uludag fir bonded with some adhesives on withdrawal strengths of beech dowel pins in composite materials," BioResources 4(4), 1682-1693.

Latibari, J.A., Ghofrani, M., and Noori, H. (2005). "Investigation the holding strength of dowel joint constructed of particleboard," Iranian Journal of Agricultural Sciences 11(1), 135-148.

Maleki, S., Dalvand, M., Rostampour, H. A., and Faezipour, M. (2013). "The effect of adhesive types and dovetail fitting height on stress carrying capacity of Miter Frame corner joints constructed of particleboard and Medium Density Fiberboard (MDF), "Journal of Forest and Wood Products 66(2),203-214.

Maleki, S., Derikvand, M., Dalvand, M., and Ebrahimi, G. (2012). 'Load-carrying capacity of mitered furniture corner joints with dovetail keys under diagonal tension load,"Turkish Journal of Agriculture and Forestry 36(5), 636-643.

Noll, T. (2007). Woodworkers Joint Book: The Complete Guide to Wood Joinery, Apple Press, Rossendale,London.

Obataya, E., and Norimoto, M. (1999). "Acoustic properties of a reed (Arundo donax L.) used for the vibrating plate of a clarinet," Journal of Acoustical Society of America 106(2), 1106-1110. 
Roohnia, M., Bremaud, I., Guibal, D., and Manouchehri, N. (2006). NDT-lab: "Software to evaluate the mechanical properties of wood," Proceedings of the International Conference of ESWM4+Cost Action, Florence, Italy.

Wegst, U. K. G. (2006). "Wood for sound,” American Journal of Botany 93(10), 1439-1448.

Zhang, J. L., and Eckelman, C. A. (1993). "The bending moment resistance of singledowel corner joints in case construction," Forest Products Journal 43(6), 19-24.

Article submitted: August 4, 2019; Peer review completed: November 28, 2019; Revised version received: February 5, 2020; Second revised version received: March 26, 2020; Published: April 3, 2020.

DOI: $10.15376 /$ biores. 15.2.3787-3798 